\title{
Design Considerations of a pair of power leads for Fast-Cycling Superconducting Accelerator Magnets operating at 2 Tesla and $100 \mathrm{kA}$
}

\author{
Yuenian Huang, Steven Hays, Henryk Piekarz, Gijsbert de Rijk and Lucio Rossi
}

\begin{abstract}
Recently proposed injector accelerator, Low Energy Ring (LER) for the LHC and fast cycling accelerators for the proton drivers (SF-SPS at CERN and DSF-MR at Fermilab) require that a new magnet technology be developed. In support of this accelerator program, a pair of power leads needs to be developed to close the loop between the power supply and accelerator system. The magnet proposed to be used will be a modified transmission line magnet technology that would allow for accelerator quality magnetic field sweep of $2 \mathrm{~T} / \mathrm{s}$. The transmission line conductor will be using HTS technology and cooled with supercritical helium at $5 \mathrm{~K}$. The power leads consist of two sections; upper one is a copper and lower section will be using HTS tapes. The accelerator magnet will be ramped to 100 $\mathbf{k A}$ in a second and almost immediately ramped down to zero in one second. This paper outlines the design considerations for the power leads to meet the operational requirements for the accelerator system. The power leads thermal analysis during the magnet powering cycle will be included.
\end{abstract}

Index Terms - Superconducting magnets, fast cycling accelerator, HTS superconductor, transmission line magnet, AC losses.

\section{INTRODUCTION}

$\mathrm{T}$ HE long-baseline neutrino oscillation search experiments require very high intensity neutrino beams. In support of this search two magnet systems using Fast-Cycling Superconducting Accelerator Components have been proposed [1]. All magnets in the entire accelerator ring would be powered by a single transmission line conductor with a pair of the current leads, and a single power supply. The total current has to be carried from room temperature power supply to the transmission line magnet operated at helium temperature would be only $100 \mathrm{kA}$. As a comparison, the LHC at CERN requires a total current more than 3,000 kA. The power supply system required for the proposed accelerator will be presented in the companion paper [2]. A conventional current leads has been designed and developed for the transmission line magnet technology for the VLHC proposal which is operated at 100 kA DC current [3]. This paper describes the power leads design considerations with a ramping current from zero to 100 $\mathrm{kA}$ in one second and then almost immediately ramping down

Manuscript received August 28, 2007. This work was supported in part by the U.S. Department of Energy under Contract DE-AC02-07CH11359.

Y. Huang, S. Hays, H. Piekarz are with FERMILAB, Batavia, Il 60510, USA (phone: 630-840-4896; fax: 630-840-6724; e-mail: huangy@fnal.gov).

G. de Rijk, and L. Rossi are with CERN, Geneva 23, Switzerland. to zero in one second. Fig. 1 shows the current ramping patterns required for the proposed fast-cycling accelerator magnet DSF-MR only. This current ramping pattern is assumed to be continued this way as long as accelerator system requires.

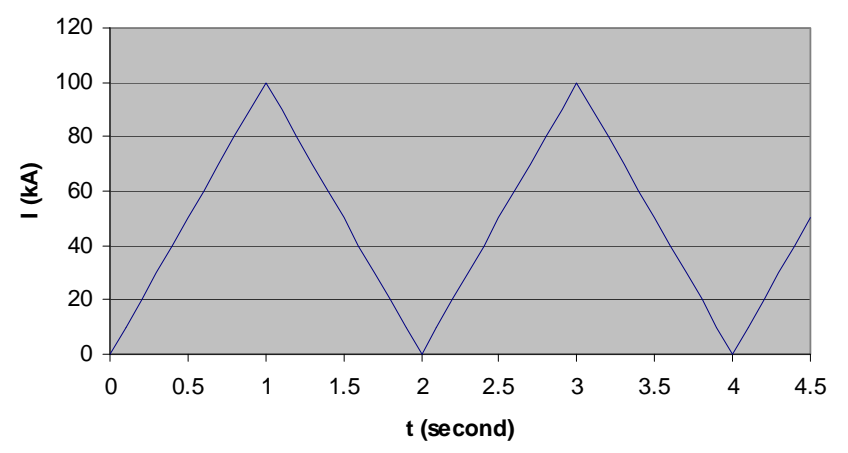

Fig.1. Proposed DSF-MR accelerator magnet ramping profiles, the magnet is ramped to $100 \mathrm{kA}$ in one second and then ramped down to zero in one second.

Most of the power leads were designed based on its nominal operating DC current since the magnet will be working at that DC current most of the time. The magnet ramp rate is usually in the neighborhood of $20 \mathrm{~A} / \mathrm{s}$, such as LHC magnets. For the DSF-MR magnets, the required ramp rate will be $100 \mathrm{kA}$ per second. Both maximum Joule heating and averaged Joule heating generated in the power leads during magnet ramping will be considered before the power leads detailed design study started.

\section{POWER LEADS CONVENTIONAL SECTION}

\section{A. Power leads operating at DC current}

Both conventional current leads and HTS current leads will have upper section which is usually made of copper material. So we will start with copper section design consideration first.

A pair of current leads has been designed and developed for the VLHC program which is operated at $100 \mathrm{kA} \mathrm{DC}$ current. The power leads has been tested and operated at 104 kA successfully for a short period of time. The helium consumption rate is about $3 \mathrm{~g} / \mathrm{s}$ per lead at standby mode and 6 $\mathrm{g} / \mathrm{s}$ at its full current. The leads cold end is connected to the nine LTS cables directly with soft-solder and leads are cooled with helium supplied at the cold end. The leads heat exchange section is separated by anodized aluminum plates along its 
length to form multiple smaller sections. The helium vapor is then guided by the G-10 blocks and anodized aluminum plates so that helium stream is forced flowing across the copper rods to generate higher heat transfer coefficient between helium streams and copper rods. Detailed leads requirements, design details and assembly work can be found in [3]. The copper leads can be used for the DSF-MR project with some modifications at both warm end and cold end to have a proper connection and satisfy the operation requirements.

All gas cooled current leads design started with the energy equation which consists of three components; heat conduction along the leads length; Joule heating generated within the leads and cooling capacity provided by the helium gas. If a control volume is taken to include whole leads, the energy in will be Joule heating plus the heat conduction at warm end while energy out equals to the cooling capacity of helium plus heat conduction at the leads cold end. For an optimized designed gas cooled current leads the Joule heating generated in the leads must be matching the cooling capacity of the helium gas so that leads can operate without thermally running away. The helium flow can be either generated by the heat conduction at the leads cold end called self sustained cooling mode or supplied at the cold end with supercritical helium to remove the heat. The maximum helium gas cooling capacity will be the enthalpy difference between its room temperature and liquid helium temperature values. The helium gas cooling capability will be $1.54 \mathrm{~kW}$ per $1 \mathrm{~g} / \mathrm{s}$ of helium flow if helium vapor is allowed to warm up to $300 \mathrm{~K}$ from $4.2 \mathrm{~K}$. For an optimized designed current leads operated at $100 \mathrm{kA}$, a helium flow of $5.2 \mathrm{~g} / \mathrm{s}$ will provide about $8 \mathrm{~kW}$ cooling power. The corresponding Joule heating at that current rating must be equal or below $8 \mathrm{~kW}$ (or $80 \mathrm{mV}$ voltage drops across the leads length). If the leads are operated in the standby mode, meaning that no current in the leads, its electrical resistance is lower than its normal operation conditions due to lower leads temperature profiles including warm end temperature below its designed temperature at $300 \mathrm{~K}$ and higher copper rods RRR value.

TABLE I

\section{KA DC CURRENT LEAD PARAMETERS}

\begin{tabular}{lll}
\hline \hline \multicolumn{1}{c}{ Parameters } & \multicolumn{1}{c}{ Units } & \multicolumn{1}{c}{ Descriptions } \\
\hline Operating current, DC & {$[\mathrm{kA}]$} & 100 \\
Lead material & {$[-]$} & Copper \\
Lead length & {$[\mathrm{m}]$} & 1.65 \\
Total cross sectional area & {$\left[\mathrm{mm}^{2}\right]$} & 6400 \\
Total surface area & {$\left[\mathrm{m}^{2}\right]$} & 6.65 \\
RRR & {$[-]$} & 80 \\
Resistance at room temperature & {$[\mu \mathrm{ohms}]$} & 4 \\
Resistance at operation mode & {$[\mu \mathrm{ohms}]$} & 0.8 \\
Measured resistance & {$[\mu \mathrm{ohms}]$} & 0.5 \\
Highest operation current & {$[\mathrm{kA}]$} & 104 \\
\hline \hline
\end{tabular}

Our experiences showed that the leads electrical resistance could be as low as $60 \%$ of its nominal value. For example, our measured data showed that the leads resistance is only 0.5 $\mu$ ohms compared to its nominal value at $0.8 \mu$ ohms. The temperature profiles along the leads length never reached optimized designed one, meaning that warm end temperature gradient is not zero so that extra heat must be conducted to the leads from its warm end, causing icing on the leads warm end. The heat leak at the leads cold end by conduction for an optimized designed current leads carrying $100 \mathrm{kA}$ should be around $104 \mathrm{~W}$ while temperature gradient at warm end is zero.

The main parameters of $100 \mathrm{kA}$ current leads designed for the superconducting transmission line magnet is listed in the Table I.

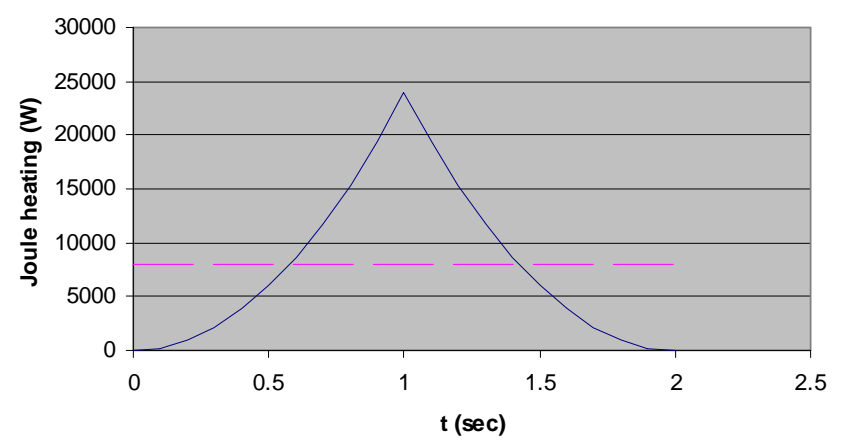

Fig. 2 Joule heating generated in the power leads when powered with the ramping current shown in Fig. 1. The solid line shows instant Joule heating while dashed line is averaged Joule heating during ramping period. The leads resistance is $2.4 \mu \mathrm{ohms}$.

\section{B. Power leads during current ramping}

The fast-cycling accelerator magnet will be using modified superconducting transmission line magnet technology which will be ramped up and down according to the current ramping patterns in Fig. 1. The total inductance of transmission line magnet is in the range of $0.02 \mathrm{H}$. Both transmission line conductor and current leads will observe a voltage as high as 2,000 Volts during operations. The leads cold end will be soft soldered to the transmission line magnet HTS cables (162 tapes total) directly. Each HTS cable will share a maximum current up to $617 \mathrm{~A}$ at a maximum operation current $100 \mathrm{kA}$. The transmission line magnet will be cooled by forced flow supercritical helium just like the way CICC type of magnet cooled. Superconducting cables is contained in a stainless steel conduit and supercritical helium is flowing surround the HTS tapes to remove the any heat generated within the cable. The detailed design study will start soon.

TABLE II

DSF-MR POWER LEADS MAIN PARAMETERS

\begin{tabular}{lll}
\hline \hline \multicolumn{1}{c}{ Parameters } & Units & \multicolumn{1}{c}{ Descriptions } \\
\hline Peak operating current & {$[\mathrm{kA}]$} & 100 \\
Lead material & {$[-]$} & Copper \\
Lead length & {$[\mathrm{m}]$} & 1.65 \\
Number of rods & {$[-]$} & 255 \\
Copper rod diameter & {$[\mathrm{mm}]$} & 3.3 \\
Total cross sectional area & {$\left[\mathrm{mm}^{2}\right]$} & 2181 \\
Total surface area & {$\left[\mathrm{m}^{2}\right]$} & 4.36 \\
RRR & {$[-]$} & 80 \\
Average Joule heating & {$[\mathrm{W}]$} & 8,000 \\
Electrical resistance at RT & {$[\mu \mathrm{ohms}]$} & 12 \\
Electrical resistance at standby mode & {$[\mu \mathrm{ohms}]$} & 2.4 \\
Maximum Joule heating & {$[\mathrm{W}]$} & 24,000 \\
Maximum voltage observed & {$[\mathrm{V}]$} & 2,000 \\
\hline \hline
\end{tabular}


The leads resistances are estimated to be $9 \mu$ ohms and 1.8 $\mu$ ohms at room temperature and at operation conditions, respectively. The maximum Joule heating generated in the current leads will be $24 \mathrm{~kW}$ at operating current of $100 \mathrm{kA}$. The average Joule heating is $8 \mathrm{~kW}$ and hence the required helium gas flow will be less than $6 \mathrm{~g} / \mathrm{s}$, the same the one designed for VLHC transmission line magnet. However, the leads size will be smaller than the one carrying $100 \mathrm{kA}$ DC current.

Fig. 3 shows the Joule heating curve and its average value during the current ramping period for the case when leads resistance is $0.8 \mu \mathrm{ohms}$. Since Joule heating is proportional to its resistance, Joule heating will be reduced by 3 times.

If DSF-MR magnet is ramped in a pattern shown in Fig. 1, then the Joule heating generation curve is shown in Fig. 2 and other main parameters of the leads are listed in Table II. The leads will be cooled with supercritical helium supplied from the cold end. The detailed leads thermal response analysis to the current ramping pattern will be needed so that designed leads can be operated safely without running away risk.

\section{POWER LEADS INSULATION ISSUES}

The DSF-MR magnets and the power leads will be ramping up and down all the time so that it is subject to a high voltage up to $2 \mathrm{kV}$. The electrical insulation between the leads and cryostat and helium supply line is needed. The plan is to use Nomax to insulate the leads from the cryostat and helium supply line just like the way applied to the transmission line conductors. In the VLHC project, two G-10 plates are used to insulate the leads from the cryostat and ceramic to insulate the helium supply line from the leads. The experiences gained during the VLHC project can be applied directly to the DSFMR project.

\section{LEADS WARM END CONSIDERATIONS}

The connection between the current leads warm end and the power supply will be using bus work. The bus work cross section will be $25 \mathrm{~mm}$ by $100 \mathrm{~mm}$ and there is $12.7 \mathrm{~mm}$ cooling at the center. The Joule heating generated within the bus work will be cooled by low conductivity water (LCW) flowing in the cooling hole. This type of bus work resistance is $7 \mu \mathrm{ohms}$ per meter at 40 degree C. The challenge part will be the space restrictions at the leads warm end. The two leads should be separated as far as the power supply allows to giving us enough space to arrange the 8 bus bars coming out of power supply, each branch will be carrying $12.5 \mathrm{kA}$. The thermal design work for the warm end bus work should be straight forward and relatively easy.

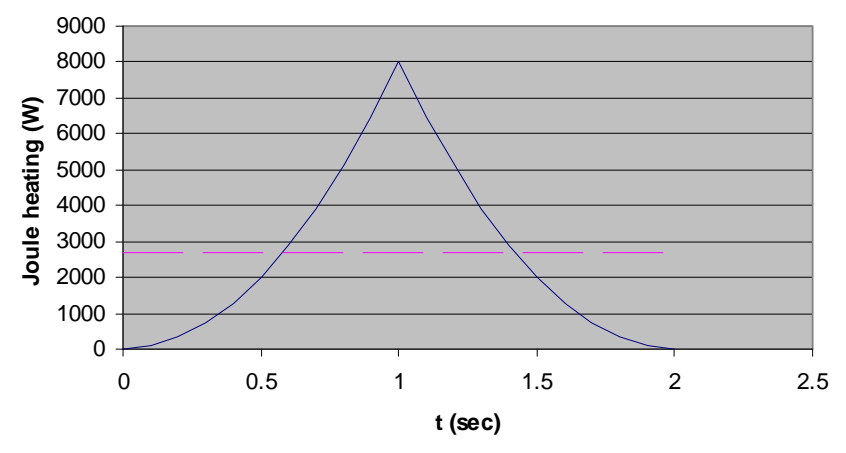

Fig. 3 Joule heating generated in the power leads when powered with the ramping current shown in Fig. 1. The solid line shows instant Joule heating while dashed line is averaged Joule heating during ramping period. The leads resistance is $0.8 \mu \mathrm{ohms}$.

\section{LEADS COLD END CONSIDERATIONS}

The leads copper section cold end will be connected directly to the HTS tapes of transmission line magnet conductors. There will be six HTS bundles coming out of magnet and each bundle consists of 27 tapes. The plan is to soft solder each bundle directly to the cold end. The leads cold end design is shown in Fig. 4. The current plan is to use supercritical helium to cool both transmission line conductor and current leads. As can be seen from the picture, the helium coming out of each of six conductors will be collected at the leads cold end and gone through the four holes at the bottom to enter the leads heat exchange section to cool the leads. The estimated critical current of the HTS conductor will be two times above its operation condition at $100 \mathrm{kA}$ and $5 \mathrm{~K}$.

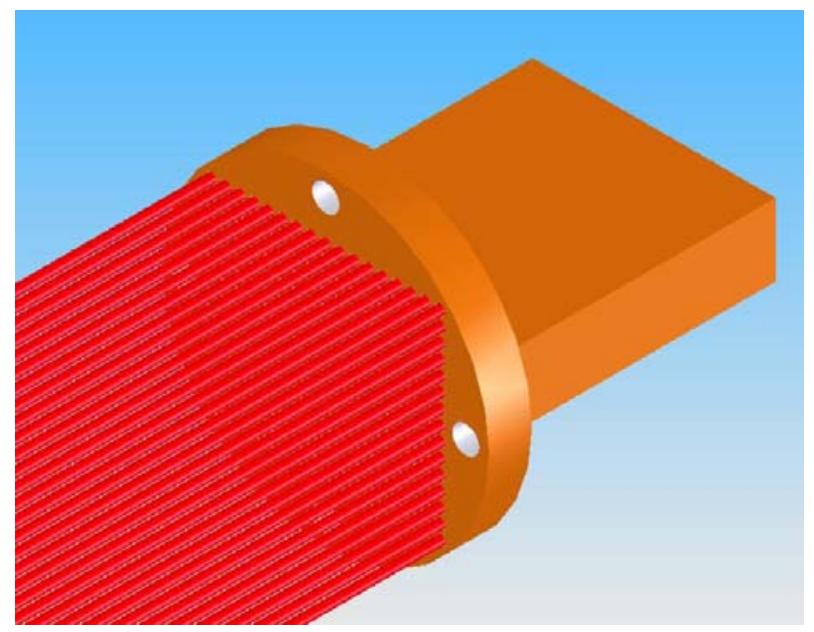

Fig. 4 Leads cold end design showing both cold end and heat exchange section consisting of multiple copper rods. The helium coming out of transmission line magnet will be collected at the cold end box before entering the heat exchange section to cool the copper rods

\section{SUMMARY}

A pair of power leads is needed for the fast cycling accelerator magnet system. The design study showed that a conventional leads made of copper rods is suitable for that application. The experiences gained during the VLHC project 
can be used for this project. The helium consumption should be in the range of $6 \mathrm{~g} / \mathrm{s}$ for each lead. The heat leak into the helium bath will be further reduced since the HTS cables are chosen to be used as the transmission line conductor. The initiation of the $R \& D$ program for the accelerator magnets powered by the HTS type superconductor is well warranted. More detailed design study and some experimental work are needed to confirm all calculations and estimations are suitable.

\section{REFERENCES}

[1] Henryk Piekarz, "Design Considerations for Fast-Cycling Superconducting Accelerator Magnets of 2 Tesla B-Field Generated by a Transmission line Conductor of up to 100kA Current. Submitted MT-20 August 272007.

[2] S. Hays, H. Piekarz, H. Pfeffer, B. Claypool, G. de Rijk, L. Rossi "Design Consideration of a Power Supply System for Fast Cycling Superconducting Accelerator Magnets Operating at 2 Tesla and 100 kA" MT- 20, 2007.

[3] Y. Huang, S. Hays, H. Piekarz, G. de Rijk, L. Rossi "The development of $100 \mathrm{kA}$ Current Leads for a Superconducting Transmission Line Magnet”, MT - 19, Genova, Italy, 2005. 